\title{
Análise de frequência das ações técnico-táticas competitivas no taekwondo: uma revisão
}

\author{
Paula AVAKIAN ${ }^{1}$, Bianka MIARKA ${ }^{*}$, \& Abdallah ACHOUR JUNIOR ${ }^{3}$ \\ 1 Universidade de São Paulo - USP (Brazil) \\ ${ }^{2}$ Universidade Federal de Pelotas - UFPel (Brazil) \\ ${ }^{3}$ Universidade Estadual de Londrina (Brazil)
}

Recepción: 30/12/2015; Aceptación: 20/03/2016; Publicación: 28/02/2017.

\section{Resumo}

ORIGINAL PAPER

0 taekwondo (TKD) é um esporte de combate que focaliza em chutes na cabeça, giratórios, e saltos. A enfase em combinações técnico-táticas com velocidade e agilidade é uma característica essencial dessa modalidade. Portanto, esse artigo objetiva contribuir com uma análise crítica sobre ações técnico-táticas de taekwondistas, utilizando momentos relativos de esforço e pausa em competições oficiais. Essa revisão investigou arranjos táticos (i.e., ataques, defesas e bloqueios), performance técnica (pontos), chutes e socos, referentes a categoria de peso, classe de idade e gênero. De fato, as modificações das regras nos anos atuais aumentou as ações defensivas entre adultos, com cerca de $50 \%$ das ações em ataques, seguido de $30 \%$ de defesas e $20 \%$ de ações de bloqueio. Enquanto juvenis tendem a adotar uma estratégia ofensiva, com cerca de $90 \%$ das ações em ataques. Desde a introdução do sistema eletrônico, atletas de alto rendimento necessitam executar técnicas precisas e corretas para conquistar pontuação, por isso, atletas de elite tem utilizado técnicas de curta distância com chutes realizados pela perna de trás. Essa ação mostra eficácia em pontuar e auxilia competidores no aumento da capacidade defensiva e em contra-ataques. Por sua vez, programas de treinamento precisam ser específicos diante das regras, necessidades de categorias de peso, gênero e idade em atletas de elite no TKD. Palavras-chave: artes marciais; desportos de combate; análise de performance; psicologia do esporte; controle motor.

\section{Analysis of the frequency of technical-tactical actions in taekwondo: a review \\ Abstract}

Taekwondo (TKD) is a combat sport, focusing on headheight kicks, spinning kicks and skipping. The emphasis on technical-tactical combinations with speed and agility is an essential characteristic of this modality. Therefore, this review aims to contribute to the critical analysis of technical-tactical actions of TKD athletes, using relative effort and pause moments of official competitions. This review investigated tactical arrangements (i.e., attacks, defenses and blocks), technical performance (points), kicks and punches, regarding to weight category, age class and gender. In fact, rule changes in recent years have increased defensive actions in the senior category, with about $50 \%$ of actions in attacks, followed by $30 \%$ in defenses and $20 \%$ in blocking actions. While juniors tend to adopt an offensive strategy, with about $90 \%$ of the actions in attacks. Since the introduction of the scoring electronic system, high-performance athletes need to perform accurate and correct techniques to achieve scoring, so elite athletes have used short-distance techniques with kicks from the back leg. This action shows effectiveness in scoring and assists competitors in increasing defensive capability and counter-attacks. Consequently, training programs need to be specific to the rules, weight divisions, gender and age categories in elite athletes in TKD.

\section{Análisis de la frecuencia de acciones técnico- tácticas en taekwondo: una revisión}

\section{Resumen}

El taekwondo (TKD) es un deporte de combate basado en patadas altas a la cabeza, patadas giratorias y saltos. Las combinaciones técnico-tácticas veloces y ágiles son una característica esencial de esta disciplina. Esta revisión contribuye al análisis crítico de las acciones técnico-tácticas de los atletas de TKD, estudiando los momentos de pausa y esfuerzo propios de los combates en competiciones oficiales. Esta revisión investigó las disposiciones tácticas (i.e., ataques, defensas y bloqueos), rendimiento técnico (puntos), patadas y golpes, según la categoría de peso, edad y género. De hecho, los cambios de reglas acaecidos durante estos años han incrementado las acciones defensivas en seniors, con alrededor del $50 \%$ de acciones ofensivas, seguidas del 30\% y $20 \%$ de acciones defensivas y bloqueos respectivamente. Los juveniles tienden a adoptar una estrategia ofensiva, con aproximadamente el $90 \%$ de acciones ofensivas. Desde la introducción del sistema electrónico de puntuación, los atletas de alto rendimiento necesitan ejecutar técnicas muy precisas y correctas para lograr puntuar. Por ello, los atletas de élite utilizan técnicas a corta distancia con patadas de la pierna retrasada. Esta acción demuestra eficacia para lograr puntos y ayuda a los competidores a aumentar su capacidad defensiva y en sus contraataques. En consecuencia, los programas de formación para atletas de élite de TKD deberían adaptarse a las reglas de competición, categorías de peso, sexo y grupos de edad.

*E-mail: miarkasport@hotmail.com 
Keywords: martial arts; combat sports; performance analysis; sport psychology; motor control.
Palabras clave: artes marciales; deportes de combate; análisis de rendimiento; psicología del deporte; control motor.

\section{Introdução}

O taekwondo (TKD) é um esporte de combate acíclico, com oito minutos de esforço intermitente e variado, distribuídos em três rounds de dois minutos cada, intervalados por um minuto de pausa (World Taekwondo Federation - WTF, 2017; Kim, 2006). Durante o combate, os lutadores tentam pontuar através de ações potentes e rápidas, como socos no tronco e chutes na cabeça e no tronco, sendo mais frequente a utilização dos chutes (Kazemi, De Ciantis, \& Rahman, 2013; Menescardi, et al., 2012; Falcó, Landeo, Menescardi, Bermejo, \& Estevan, 2012). Atletas de elite apresentam perfil motor diferenciado e modo de combate bastante próprio, por isso, investigar como os ataques no colete, com valor de um ponto, chutes com giro no colete ou na cabeça que obtém de três até quatro pontos estão sendo realizados, pode aprimorar o conhecimento sobre fatores determinantes do resultado da luta (WTF, 2017, Cular, Krstolovic, \& Tomljanovoc, 2011; Slimani, Chaabène, Miarka, \& Chamari, 2016; Tornello, et al., 2014). Além da somatória de pontos, sabe-se que a vitória pode ser alcançada mediante nocaute ou por diferença de pontos, ou seja, quando um dos atletas obtém 12 pontos de diferença no final do segundo round ou a qualquer momento do terceiro round, morte súbita, desistência, desqualificação do adversário ou declaração punitiva do adversário pelo árbitro (WTF, 2017; Kruszewski, Jagiełło, \& Pyzel, 2009).

A importância desses fatores permite mais ênfase sobre as análises notacionais em esportes de combate (Kim, Kwon, Yenuga, \& Kwon, 2010), as quais mostram informações técnico-táticas durante o intervalo de esforço que varia em função das ações do TKD (Marcovoc, Vucetic, \& Cardinale, 2008; Ouergui, Haddad, Hammami, \& Chamari, 2014), que podem estar relacionadas com tipos de deslocamentos, esquivas e bloqueios associados com ataques e contra-ataques (Fargas, 1990). Em 2016, a WTF realizou modificações nas regras importantes no processo de esportivização dessa modalidade (WTF, 2016), por exemplo, a introdução de capacetes eletrônicos e um maior valor para chutes giratórios no tronco, que passaram de dois para três pontos. Além disso, técnicas realizadas em clinch agora são passíveis de kyongo (penalização por ato proibido), pois ao realizar ataque em situação como essa, o atleta, normalmente, segura ou empurra o adversário, o que é proibido (WTF, 2016). Adicionalmente, houve a modificação do tempo médico, que antes cedia um minuto para recuperação do atleta, mas agora passou a ser passível de desclassificação, caso o atleta não levante até o terceiro pedido médico para levantar-se (WTF, 2016). Essas modificações objetivam tornar o TKD mais atrativo ao público, porém também podem modificar a estrutura temporal do combate, assim como as ações técnico-táticas determinantes para a modalidade.

Para futuras intervenções em treinamentos (Slimani, et al., 2016), para prevenção de lesões (Lystad, Swain, \& Graham, 2013) e até mesmo para compreensão sobre a estrutura da luta de TKD (Bridge, Jones, \& Drust, 2011), estudos diacromiais sobre análises de performance são necessários, pois proporcionam informações que contribuem para a interpretação do esforço específico requerido, esse tipo de investigação permite inferir o plano estratégico escolhido por atletas, de acordo com as demandas do combate ao longo do processo competitivo (Del Vecchio, Silva, \& Farias, 2015; Kazemi, Perri, \& Soave, 2010). Os primeiros estudos no TKD caracterizam a relação esforço-pausa (E:P) da luta (Pieter, 1991; Heller, et al., 1998). O E:P é apresentado na literatura por valores que oscilam de 1:2 a 1:7, considerando populações diversificadas, esses dados não são consensuais e modificam conforme idade, sexo e nível competitivo dos atletas (Bridge, Jones \& Drust, 2011; Campos, Bertuzzi, Dourado, Santos \& Franchini, 2012; Casolino, et al., 2012; Iglesias, Gasset, González, \& Anguera, 2010).

Ultimamente, os momentos de esforços estão sendo separados em baixas e altas intensidades (Fargas, 1990; Chaabène, et al., 2014; Tornello, et al., 2013). As ações de alta intensidade são associadas com técnicas que exigem elevados níveis de potência - como chutes e socos desferidos em situações de ataque ou defesa (Menescardi, et al., 2012; Kazemi, Casella, \& Perri, 2009). Enquanto as ações de baixa intensidade são relacionadas com movimentações em step e saltitos, próprios para momentos do combate nos quais se objetiva analisar e preparar estratégias 
prévias à cada situação de ataque e defesa (Santos, Franchini, \& Lima-Silva 2011; Matsushigue, Hartmann, \& Franchini, 2009). Apesar de as pesquisas atuais ainda realizarem análises isolando variáveis de tempo-movimento - dada a escassez de metodologias que permitam verificar a interação entre as ações técnico-táticas -, já se sabe que a luta de TKD não é apenas um conjunto de situações de esforços fragmentados (Gómez-Castañeda, 2005). Os atletas combinam ações para originar diferentes arranjos, objetivando efeito favorável no resultado da luta (Kazemi, Waalen, Morgan, \& White, 2006). Portanto, saber a frequência e a pontuação das ações determinantes para vitória na modalidade pode auxiliar em práticas contextualizadas. Por exemplo, treinamentos com frequência e intensidade próximos à situação competitiva favorecem a criação de estratégias adequadas às situações de E:P, considerando a eficácia para obter pontuação (Falcó, Estevan, Alvarez, Morales-Sánchez, \& Hernández-Mendo, 2014; Pyciarz, 2011). A fim de caracterizar e justificar o presente estudo sobre a análise de performance competitiva no TKD, a revisão de artigos analisa de forma meticulosa as investigações sobre o assunto e descreve os resultados de forma crítica, abordando problemas metodológicos e conceituais.

Espera-se que essa pesquisa possa contribuir para realização de um sumário sobre análises de atletas para que seja observada com mais criticidade as relações de esforço e pausa e as ações técnico-táticas por categoria de peso, sexo, classe de idade e nível competitivo (González, 2011; González, Iglesias, Mirallas, \& Esparza, 2011; Gómez-Castañeda, 2005; Pieter, 1991; Kruszewski, Kúzmicki, Podchul, \& Kruszewski, 2014). Além disso, essa pesquisa sobre a literatura possibilita a criação de modelos práticos de análise para aplicabilidade e melhora da compreensão sobre como os atletas atuais com maior destaque e prestígio internacional atuam em combates a partir da identificação de ações determinantes e efetivas em combate. Portanto, essa revisão objetiva sintetizar informações sobre análise de performance no TKD, realizando um sumário sobre as investigações relacionadas com análises das características sobre a luta no que se refere ao esforço: pausa, tempo-movimento e a os aspectos técnico-táticos dos combates competitivos.

\section{Métodos}

Os dados foram obtidos a partir de pesquisas publicadas em revistas científicas, disponíveis física e eletronicamente, com ou sem livre acesso, bem como por correspondência pessoal (até agosto de 2016). O presente estudo utilizou as seguintes bases de dados: Plataforma CAPEs, PubMed, Scopus, SportDiscus, PsycINFO, PsycARTICLES e Medline. As buscas em bases de dados eletrônicas foram realizadas empregando as seguintes palavras-chave e/ou termos específicos indexados, traduzidos para inglês ou para o espanhol: "Taekwondo", "taekwon-do", "tae kwon do" combinado com "técnica", "tática" e/ou "técnico-tática", em combinação com os termos "análise de performance", "análise de tempo-movimento", "relação esforço-pausa", "análise técnico-tática", "análise notacional", "análise observacional" e "análise de luta".

\subsection{Critérios de inclusão e exclusão}

A investigação contemplou estudos publicados em português, inglês e espanhol. 0 critério de exclusão concerne à publicação que não estivesse nas bases de dados eletrônicas apresentadas e/ou que não tivesse sido submetida à revisão por pares. Foram selecionados estudos com descrições observacionais inéditas ou cujos testes experimentais mostrassem efeito da intervenção sobre os parâmetros de tempo-movimento, técnico-táticos e nas relações de esforço e pausa. Os artigos foram examinados pela própria validade interna sob os critérios da escala de PEDro (De Morton, 2009) e remetem à: (1) garantir validade interna, utilizando pesquisa com grupo de controle e/ou aleatorização na distribuição de grupos, se houvesse intervenção; (2) garantir validade interna, com estudos aleatórios de controle e distribuição cega, em caso de intervenção; (3) garantir validade interna, introduzindo estudos com instrumentos com validação e/ou com alta confiabilidade, partindo de condições contextuais e número amostral entre os grupos semelhantes no que diz respeito ao resultado das análises dos indicadores de tempo-movimento, técnico-táticos e da relação esforço:pausa, e; (4) garantir validade externa, incluindo investigações com mortalidade experimental mínimae, com estimativa amostral capaz de revelar as características da população estudada, a identificação da qualidade dos estudos está na Tabela 1. 
Tabela 1. Avaliação pela escala de PEDro dos artigos examinados pela própria validade interna.

\begin{tabular}{|c|c|c|}
\hline Critérios & Sim & Não \\
\hline - Os critérios de elegibilidade foram especificados & 30 & 05 \\
\hline - Os sujeitos foram aleatoriamente distribuídos por grupos & 23 & 12 \\
\hline - A alocação dos sujeitos foi secreta & 31 & 04 \\
\hline $\begin{array}{l}\text { - Inicialmente, os grupos eram semelhantes no que diz respeito aos } \\
\text { indicadores de prognóstico mais importantes }\end{array}$ & 32 & 03 \\
\hline - Todos os sujeitos participaram de forma cega no estudo & 22 & 13 \\
\hline $\begin{array}{l}\text { - Todos os pesquisadores que administraram a pesquisa fizeram-no de } \\
\text { forma cega }\end{array}$ & 35 & 00 \\
\hline $\begin{array}{l}\text { - Todos os avaliadores que mediram pelo menos um resultado-chave, } \\
\text { fizeram-no de forma cega }\end{array}$ & 12 & 23 \\
\hline $\begin{array}{l}\text { - Mensurações de pelo menos um resultado-chave foram obtidas em mais } \\
\text { de } 85 \% \text { dos sujeitos inicialmente distribuídos pelos grupos }\end{array}$ & 35 & 00 \\
\hline $\begin{array}{l}\text { - Todos os sujeitos a partir dos quais se apresentaram mensurações de } \\
\text { resultados receberam o tratamento ou a condição de controle conforme } \\
\text { a alocação ou, quando não foi esse o caso, fez-se a análise dos dados para } \\
\text { pelo menos um dos resultados-chave por "intenção de tratamento" }\end{array}$ & 31 & 04 \\
\hline $\begin{array}{l}\text { - Os resultados das comparações estatísticas inter-grupos foram descritos } \\
\text { para pelo menos um resultado-chave }\end{array}$ & 35 & 00 \\
\hline $\begin{array}{l}\text { - } 0 \text { estudo apresenta tanto medidas de precisão como medidas de } \\
\text { variabilidade para pelo menos um resultado-chave }\end{array}$ & 32 & 03 \\
\hline
\end{tabular}

Cada pesquisa foi analisada, a fim de avaliar a qualidade dos estudos sobre demandas técnico-táticas, de tempo-movimento e da relação esforço e pausa obtidos em combates de TKD. Em relação à qualidade dos estudos, 30 apresentaram resposta "Sim" em mais de 70\% das questões na avaliação da qualidade. A Figura 1 mostra o fluxograma da busca.

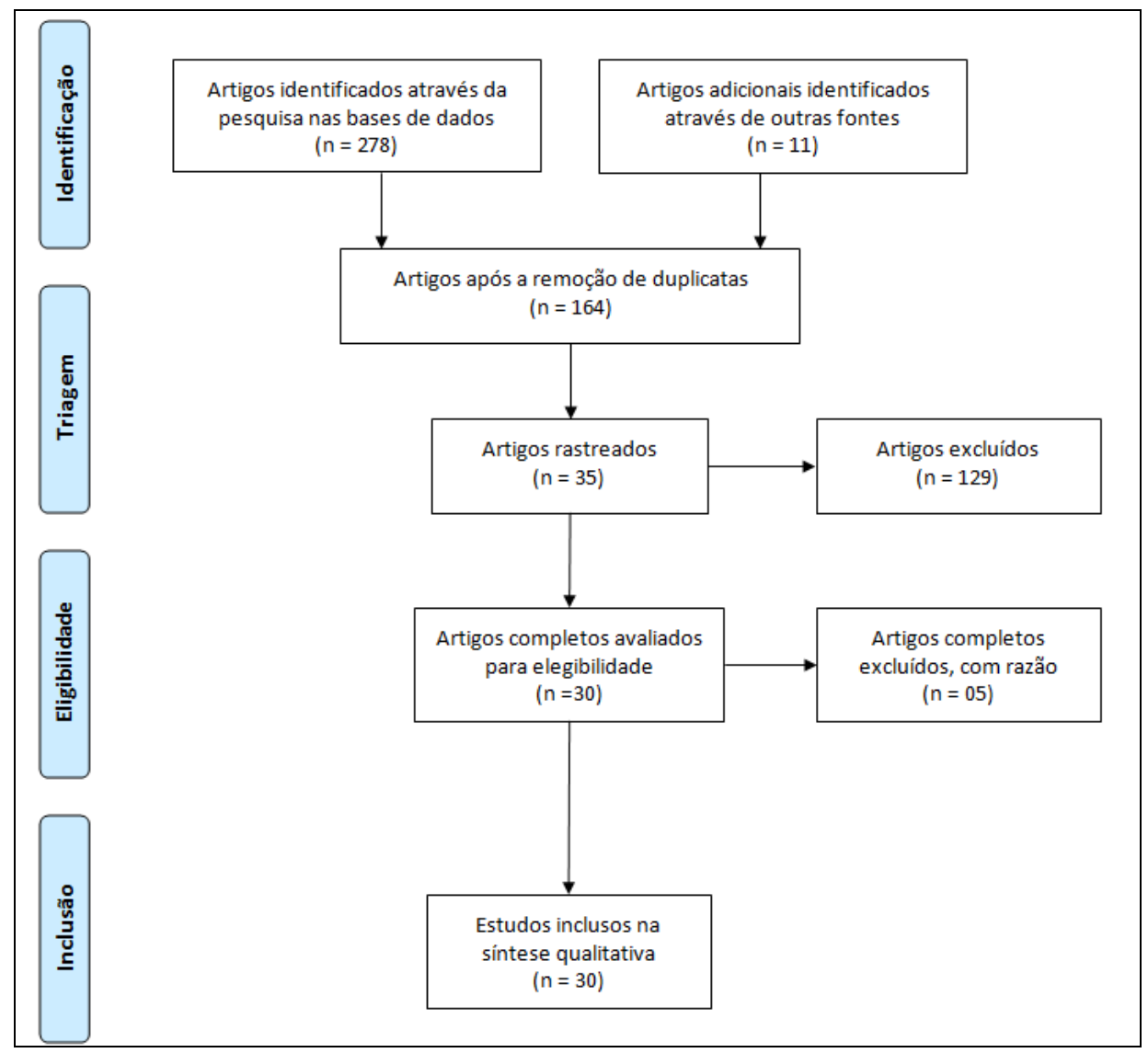

Figura 1. Fluxograma da revisão sobre análise de frequência das ações técnico-táticas competitivas no taekwondo. 
De um total de 30 publicações (Figura 1), 25 estavam escritas em inglês e cinco em espanhol, sendo que 24 tratavam de análises de ações técnico-táticas durante combates competitivos (Tabela 2) e outras seis realizaram importantes análises em treinamento de demandas competitivas e análises de combinações entre ações técnicas (Butios \& Tasika, 2007; Gómez-Castañeda, 2005; González, et al., 2011; Kim, et al., 2010; Kim, 2006; Kordi, Abdollahi, Memari, \& Najafabadi, 2011).

\section{Resultados e discussão}

A Tabela 2 mostra os artigos sobre demandas competitivas.

Tabela 2. Publicações sobre tempo-movimento e aspectos técnicos-táticos em combates de taekwondo.

\begin{tabular}{|c|c|c|c|c|}
\hline Estudo & Amostra & Delineamento & Objetivo & Resultado \\
\hline $\begin{array}{l}\text { Bridge et al., } \\
2011\end{array}$ & $\begin{array}{l}12 \text { atletas do } \\
\text { sexo } \\
\text { masculino. }\end{array}$ & $\begin{array}{c}\text { Sistema de análise } \\
\text { tempo- } \\
\text { movimento. }\end{array}$ & $\begin{array}{l}\text { Descrever tempo } \\
\text { de luta e tipos de } \\
\text { ações no combate. }\end{array}$ & 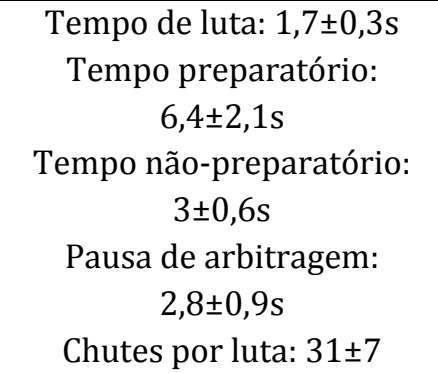 \\
\hline $\begin{array}{l}\text { Campos et al., } \\
2012\end{array}$ & $\begin{array}{l}10 \text { atletas de } \\
\text { elite do sexo } \\
\text { masculino. }\end{array}$ & $\begin{array}{l}\text { Competição } \\
\text { simulada, com três } \\
\text { rounds de dois } \\
\text { minutos e um } \\
\text { minuto de } \\
\text { intervalo entre } \\
\text { eles. Foi utilizada } \\
\text { filmagem e } \\
\text { mensuração de } \\
\text { consumo de } \\
\text { oxigênio. }\end{array}$ & $\begin{array}{c}\text { Investigar a } \\
\text { contribuição dos } \\
\text { sistemas } \\
\text { energéticos e } \\
\text { gasto energético } \\
\text { em situação de } \\
\text { combate. }\end{array}$ & $\begin{array}{c}\text { A relação esforço:pausa } \\
\text { encontrada foi de } \\
\text { aproximadamente } 1: 7 . \text { A } \\
\text { contribuição energética } \\
\text { estimada para os sistemas } \\
\text { aeróbio, anaeróbio alático e } \\
\text { anaeróbio lático foi, } \\
\text { respectivamente: } 120 \pm 22 \mathrm{~kJ} \\
(66 \pm 6 \%), 54 \pm 21 \mathrm{~kJ}(30 \pm 6 \%) \\
\text { e } 8,5 \mathrm{~kJ}(4 \pm 2 \%) .\end{array}$ \\
\hline $\begin{array}{l}\text { Casolino et } \\
\text { al., } 2012\end{array}$ & $\begin{array}{l}59 \text { atletas } \\
\text { juvenis ( } 43 \text { do } \\
\text { sexo masculino } \\
\text { e } 16 \text { do sexo } \\
\text { feminino). }\end{array}$ & $\begin{array}{c}\text { Analise de luta } \\
\text { (três rounds de um } \\
\text { minuto com um } \\
\text { minuto de } \\
\text { descanso entre } \\
\text { eles). Verificação } \\
\text { de diferenças } \\
\text { entre ações de } \\
\text { ataque e de defesa, } \\
\text { resultado de luta e } \\
\text { lateralidade. }\end{array}$ & $\begin{array}{l}\text { Analisar aspectos } \\
\text { técnico-táticos de } \\
\text { atletas juvenis em } \\
\text { competições } \\
\text { oficiais. }\end{array}$ & $\begin{array}{l}\text { Não houve diferença nos } \\
\text { quesitos gênero e resultado } \\
\text { de luta. Atletas juvenis } \\
\text { realizam mais ações de } \\
\text { ataque }(91,6 \pm 12 \%) \text { do que } \\
\text { de defesa }(8,4 \pm 12 \%) \text {. Chutes } \\
\text { desferidos com a perna de } \\
\text { trás }(94,4 \pm 7,8 \%) \text { ocorreram } \\
\text { com mais frequência do que } \\
\text { a perna da frente } \\
(5,6 \pm 7,8 \%) \text {. }\end{array}$ \\
\hline $\begin{array}{l}\text { Cerda-Kohler } \\
\text { et al., } 2015\end{array}$ & $\begin{array}{c}20 \text { atletas do } \\
\text { sexo masculino }\end{array}$ & $\begin{array}{l}\text { Obtenção das } \\
\text { medidas de } \\
\text { demanda } \\
\text { fisiológica e da } \\
\text { aceleração de } \\
\text { ações de ataque. }\end{array}$ & $\begin{array}{l}\text { Obter medidas } \\
\text { fisiológicas e da } \\
\text { aceleração dos } \\
\text { movimentos. }\end{array}$ & $\begin{array}{l}\text { Variáveis fisiológicas não } \\
\text { foram decisivas para } \\
\text { combates de TKD e o fator } \\
\text { psicológico e técnico-tático } \\
\text { apresentam maior impacto } \\
\text { na performance. }\end{array}$ \\
\hline $\begin{array}{c}\text { Cular et al., } \\
2011\end{array}$ & $\begin{array}{l}128 \text { atletas } \\
\text { elite (64 } \\
\text { homens e } 64 \\
\text { mulheres). }\end{array}$ & $\begin{array}{l}\text { Dados obtidos a } \\
\text { partir do website } \\
\text { oficial do evento. }\end{array}$ & $\begin{array}{c}\text { Estabelecer } \\
\text { diferenças em } \\
\text { características } \\
\text { morfológicas e }\end{array}$ & $\begin{array}{c}\text { Diferenças significativas } \\
\text { foram encontradas entre } \\
\text { medalhistas de ouro e outros } \\
\text { competidores para o sexo }\end{array}$ \\
\hline
\end{tabular}




\begin{tabular}{|c|c|c|c|c|}
\hline & & & $\begin{array}{l}\text { parâmetros de } \\
\text { eficácia } \\
\text { competitiva entre } \\
\text { medalhistas de } \\
\text { ouro e outros } \\
\text { competidores de } \\
\text { ambos os sexos no } \\
\text { evento. }\end{array}$ & $\begin{array}{l}\text { masculino, como a média de } \\
\text { pontuação realizada e } \\
\text { sofrida por luta e a média de } \\
\text { chutes defensivos realizados } \\
\text { no tronco. Para o sexo } \\
\text { feminino, além dos pontos já } \\
\text { citados, acrescenta-se a } \\
\text { média de chutes ofensivos } \\
\text { realizados no tronco e na } \\
\text { cabeça e a média de } \\
\text { paralizações por luta. }\end{array}$ \\
\hline $\begin{array}{c}\text { Estevan et al. } \\
2016\end{array}$ & $\begin{array}{c}86 \text { praticantes } \\
\text { do sexo } \\
\text { masculino. }\end{array}$ & $\begin{array}{l}\text { Análise por } \\
\text { questionário na } \\
\text { percepção da } \\
\text { eficácia em tática } \\
\text { das ações em } \\
\text { combate. }\end{array}$ & $\begin{array}{l}\text { Analisar a auto- } \\
\text { eficácia } \\
\text { percebida e a } \\
\text { eficácia em relação } \\
\text { ao gênero e ao } \\
\text { sucesso em } \\
\text { combate. }\end{array}$ & $\begin{array}{l}\text { Vencedores pontuam mais } \\
\text { na percepção sobre a } \\
\text { eficácia técnico-tática do que } \\
\text { não-vencedores. Vencedores } \\
\text { apresentaram maior } \\
\text { frequência de contra- } \\
\text { ataques, ataques por } \\
\text { antecipação e subsequentes } \\
\text { ataques circulares e na } \\
\text { cabeça. }\end{array}$ \\
\hline $\begin{array}{c}\text { Falcó et al., } \\
2012\end{array}$ & $\begin{array}{l}61 \text { atletas ( } 30 \\
\text { do sexo } \\
\text { masculino e } 31 \\
\text { do sexo } \\
\text { feminino). }\end{array}$ & $\begin{array}{l}\text { A performance foi } \\
\text { avaliada com base } \\
\text { em: a) tipo e altura } \\
\text { da técnica; b) } \\
\text { natureza de } \\
\text { ataque ou contra- } \\
\text { ataque e c) perfil } \\
\text { de pontuação. }\end{array}$ & $\begin{array}{l}\text { Analisar a } \\
\text { performance de } \\
\text { atletas } \\
\text { medalhistas em } \\
\text { nível nacional } \\
\text { universitário. }\end{array}$ & $\begin{array}{l}\text { Ambos os sexos realizaram } \\
\text { grande quantidade de chutes } \\
\text { circulares, seguidos de } \\
\text { chutes lineares. Houve maior } \\
\text { frequência para técnicas na } \\
\text { altura do tronco em vez de } \\
\text { rosto. Técnicas de ataque } \\
\text { foram mais utilizadas do que } \\
\text { as de contra-ataque. }\end{array}$ \\
\hline $\begin{array}{c}\text { Falcó et al., } \\
2014\end{array}$ & $\begin{array}{c}204 \text { atletas } \\
\text { universitários } \\
\text { (178 lutas). }\end{array}$ & $\begin{array}{l}\text { Análise de vídeos a } \\
\text { partir de tipo de } \\
\text { ataques e tipo de } \\
\text { contra-ataques. }\end{array}$ & $\begin{array}{c}\text { Identificar } \\
\text { características } \\
\text { táticas de sucesso } \\
\text { em atletas } \\
\text { competidores do } \\
\text { campeonato } \\
\text { nacional } \\
\text { universitário. }\end{array}$ & $\begin{array}{l}\text { Atletas realizaram mais } \\
\text { ataques do que contra- } \\
\text { ataques e vencedores } \\
\text { atacaram mais do que } \\
\text { perdedores, assim como } \\
\text { realizaram mais contra- } \\
\text { ataque antecipatório e } \\
\text { menos ataque indireto. }\end{array}$ \\
\hline $\begin{array}{c}\text { González, } \\
2011\end{array}$ & $\begin{array}{l}48 \text { atletas de } \\
\text { elite finalistas } \\
\text { do sexo } \\
\text { masculino. }\end{array}$ & $\begin{array}{l}\text { Metodologia } \\
\text { observacional } \\
\text { (fichas de } \\
\text { observação e } \\
\text { programas } \\
\text { específicos). }\end{array}$ & $\begin{array}{l}\text { Caracterizar ações } \\
\text { técnico-táticas do } \\
\text { combate de alto } \\
\text { nível masculino. }\end{array}$ & $\begin{array}{l}\text { Foram realizadas } 4961 \\
\text { ações e destas 3,35\% foram } \\
\text { penalizações. As ações } \\
\text { táticas de ataque dizem } \\
\text { respeito a 78,81\% e } 21,19 \% \\
\text { para ações de defesa. } 0 \\
\text { chute circular na altura do } \\
\text { abdômen foi a técnica mais } \\
\text { frequente, com 78,34\% das } \\
\text { ações. }\end{array}$ \\
\hline $\begin{array}{c}\text { Heller et al., } \\
1998\end{array}$ & $\begin{array}{l}\text { Atletas elite do } \\
\text { sexo masculino } \\
\text { e feminino. }\end{array}$ & $\begin{array}{l}\text { Análise tempo- } \\
\text { movimento, } \\
\text { avaliação } \\
\text { antropométrica, } \\
\text { capacidade } \\
\text { aeróbia e } \\
\text { anaeróbia, força, }\end{array}$ & $\begin{array}{c}\text { Identificar } \\
\text { parâmetros } \\
\text { antropométricos e } \\
\text { fisiológicos que } \\
\text { podem ser } \\
\text { importantes para } \\
\text { o sucesso }\end{array}$ & $\begin{array}{l}\text { A análise tempo-movimento } \\
\text { mostrou para dois rounds de } \\
\text { dois minutos um tempo } \\
\text { médio de ataque de } 3 \text { a } 5 \\
\text { segundos a cada ação. }\end{array}$ \\
\hline
\end{tabular}




\begin{tabular}{|c|c|c|c|c|}
\hline & & $\begin{array}{l}\text { tempo de reação } \\
\text { visual, função } \\
\text { pulmonar, } \\
\text { flexibilidade e } \\
\text { potência de chute }\end{array}$ & competitivo. & \\
\hline $\begin{array}{l}\text { Kazemi et al., } \\
2006\end{array}$ & $\begin{array}{l}\text { Atletas elite do } \\
\text { sexo masculino } \\
\text { e feminino. }\end{array}$ & $\begin{array}{l}\text { Dados obtidos a } \\
\text { partir do website } \\
\text { oficial do evento. }\end{array}$ & $\begin{array}{c}\text { Comparar } \\
\text { finalistas e não } \\
\text { finalistas em } 2000 .\end{array}$ & $\begin{array}{l}98 \% \text { de todas as técnicas } \\
\text { utilizadas em combate foram } \\
\text { chutes. } 52 \% \text { dos golpes } \\
\text { computados foram } \\
\text { provenientes de ações de } \\
\text { ataque. }\end{array}$ \\
\hline $\begin{array}{l}\text { Kazemi et al., } \\
2009\end{array}$ & $\begin{array}{l}\text { Atletas elite do } \\
\text { sexo masculino } \\
\text { e feminino. }\end{array}$ & $\begin{array}{l}\text { Dados obtidos a } \\
\text { partir do website } \\
\text { oficial do evento. }\end{array}$ & $\begin{array}{c}\text { Comparar } \\
\text { finalistas e não } \\
\text { finalistas em } 2004 .\end{array}$ & $\begin{array}{l}\text { Tanto atletas masculinos } \\
\text { quanto femininos utilizaram } \\
\text { golpes ofensivos e } \\
\text { defensivos de um ponto com } \\
\text { maior frequência. Homens } \\
\text { foram mais penalizados do } \\
\text { que as mulheres. }\end{array}$ \\
\hline $\begin{array}{l}\text { Kazemi et al., } \\
2010\end{array}$ & $\begin{array}{l}\text { Atletas elite do } \\
\text { sexo masculino } \\
\text { e feminino. }\end{array}$ & $\begin{array}{l}\text { Dados obtidos a } \\
\text { partir do website } \\
\text { oficial do evento. }\end{array}$ & $\begin{array}{c}\text { Comparar } \\
\text { finalistas e não } \\
\text { finalistas em } 2008 .\end{array}$ & $\begin{array}{l}\text { Utilização de mais técnicas } \\
\text { de defesa para pontuação. }\end{array}$ \\
\hline $\begin{array}{l}\text { Kazemi et al., } \\
2013\end{array}$ & $\begin{array}{c}96 \text { atletas elite } \\
\text { do sexo } \\
\text { masculino e } \\
\text { feminino. }\end{array}$ & $\begin{array}{l}\text { Dados obtidos a } \\
\text { partir do website } \\
\text { oficial do evento. }\end{array}$ & $\begin{array}{c}\text { Identificar } \\
\text { tendências nos } \\
\text { atributos } \\
\text { antropométricos e } \\
\text { estratégias } \\
\text { competitivas de } \\
\text { sucesso de atletas } \\
\text { no que diz } \\
\text { respeito à massa } \\
\text { corporal e técnica } \\
\text { de luta. }\end{array}$ & $\begin{array}{c}\text { Diferenças técnico-táticas } \\
\text { entre vencedores e } \\
\text { perdedores, que mostraram } \\
2,61 \pm 1,38 \text { e } 0,85 \pm 1,48 \\
\text { pontos ofensivos e } \\
2,33 \pm 1,84 \text { e } 1,27 \pm 1,75 \\
\text { pontos em contra-ataque, } \\
\text { respectivamente. }\end{array}$ \\
\hline $\begin{array}{l}\text { Kruszewski } \\
\text { et al., } 2009\end{array}$ & $\begin{array}{l}\text { Atletas elite do } \\
\text { sexo masculino } \\
\text { e feminino. }\end{array}$ & $\begin{array}{l}\text { Sistema de análise } \\
\text { tempo-movimento }\end{array}$ & $\begin{array}{l}\text { Caracterizar ações } \\
\text { técnico-táticas do } \\
\text { combate de alto } \\
\text { nível. }\end{array}$ & $\begin{array}{l}\text { Maior frequência de ações } \\
\text { realizadas na altura da } \\
\text { cabeça. }\end{array}$ \\
\hline $\begin{array}{l}\text { Kruszewski } \\
\text { et al., } 2014\end{array}$ & $\begin{array}{l}84 \text { atletas de } \\
\text { elite do sexo } \\
\text { feminino. }\end{array}$ & $\begin{array}{l}\text { Análise de seis } \\
\text { lutas de cada } \\
\text { categoria de peso } \\
\text { ( } \leq 49 \mathrm{~kg}, \leq 57 \mathrm{~kg} \text {, } \\
\leq 67 \mathrm{~kg}, \geq 67 \mathrm{~kg} \text { ). }\end{array}$ & $\begin{array}{l}\text { Determinar o } \\
\text { efeito das } \\
\text { mudanças na regra } \\
\text { do esporte na } \\
\text { técnica de } \\
\text { competição de } \\
\text { atletas do sexo } \\
\text { feminino. }\end{array}$ & $\begin{array}{l}\text { Aumento de golpes na região } \\
\text { do rosto e diminuição na } \\
\text { região do tronco. As ações de } \\
\text { contra-ataque são mais } \\
\text { frequentes. }\end{array}$ \\
\hline $\begin{array}{l}\text { López-López } \\
\text { et al., } 2015\end{array}$ & $\begin{array}{l}\text { Atletas elite do } \\
\text { sexo masculino } \\
\text { finalistas. }\end{array}$ & $\begin{array}{l}\text { Análise de } \\
\text { coordenadas } \\
\text { polares. }\end{array}$ & $\begin{array}{c}\text { Estabelecer } \\
\text { diferentes relações } \\
\text { acerca do } \\
\text { comportamento } \\
\text { técnico-tático e } \\
\text { pontuações entre } \\
\text { categorias. }\end{array}$ & $\begin{array}{l}\text { Sugestão para treinamento } \\
\text { de ações antecipatórias, } \\
\text { lineares e com a perna de } \\
\text { trás e também execução de } \\
\text { giro com guarda aberta } \\
\text { finalizando em fechada. }\end{array}$ \\
\hline $\begin{array}{l}\text { Marcovic et } \\
\text { al., } 2008\end{array}$ & $\begin{array}{l}13 \text { atletas de } \\
\text { elite do sexo }\end{array}$ & $\begin{array}{c}\text { Análise de } \\
\text { características }\end{array}$ & $\begin{array}{c}\text { Determinar } \\
\text { características }\end{array}$ & $\begin{array}{l}\text { Atletas de sucesso possuem } \\
\text { valor de consumo máximo }\end{array}$ \\
\hline
\end{tabular}


Avakian, P., Miarka, B., \& Achour Jr., A.

\begin{tabular}{|c|c|c|c|c|}
\hline & feminino. & $\begin{array}{c}\text { fisiológicas, } \\
\text { potência, força } \\
\text { máxima e } \\
\text { resistência de } \\
\text { força, flexibilidade, } \\
\text { agilidade e } \\
\text { potência } \\
\text { anaeróbia alática. }\end{array}$ & $\begin{array}{c}\text { físicas e } \\
\text { fisiológicas de } \\
\text { sucesso em atletas } \\
\text { do sexo feminino. }\end{array}$ & $\begin{array}{c}\text { de oxigênio ( } 41,4 \pm 4,1 \\
\mathrm{ml} / \mathrm{kg} / \mathrm{min}) \text { comparado com } \\
\text { outras atletas }(37,6 \pm 2 \\
\mathrm{ml} / \mathrm{kg} / \mathrm{min}) \text { e também } \\
\text { possuem menos valor de } \\
\text { frequência cardíaca } \\
(166,8 \pm 6,8 \text { bpm versus } \\
171 \pm 8,2 \mathrm{bpm}) .\end{array}$ \\
\hline $\begin{array}{c}\text { Matsushigue } \\
\text { et al., } 2009\end{array}$ & $\begin{array}{l}14 \text { atletas do } \\
\text { sexo } \\
\text { masculino. }\end{array}$ & $\begin{array}{c}\text { Medidas de } \\
\text { frequência } \\
\text { cardíaca e } \\
\text { concentração de } \\
\text { lactato antes e } \\
\text { após a luta e } \\
\text { também filmagens } \\
\text { das lutas. }\end{array}$ & $\begin{array}{c}\text { Determinar a } \\
\text { estrutura } \\
\text { temporal e } \\
\text { respostas } \\
\text { fisiológicas } \\
\text { durante uma } \\
\text { competição de } \\
\text { Taekwondo (estilo } \\
\text { Songahm) e } \\
\text { comparar } \\
\text { variáveis entre } \\
\text { atletas vencedores } \\
\text { e perdedores. }\end{array}$ & $\begin{array}{c}\text { A concentração de lactato } \\
\text { pós-luta foi de } \\
7,5 \pm 3,8 \mathrm{mmol} / \mathrm{L} \mathrm{e} \mathrm{a} \\
\text { frequência cardíaca alcançou } \\
183 \pm 9 \text { bpm na mesma } \\
\text { condição. Vencedores } \\
\text { utilizaram menor número de } \\
\text { técnicas. }\end{array}$ \\
\hline $\begin{array}{c}\text { Menescardi } \\
\text { et al. } 2015\end{array}$ & $\begin{array}{c}204 \text { atletas do } \\
\text { sexo } \\
\text { masculino. }\end{array}$ & Análise tática. & $\begin{array}{c}\text { Analisar o } \\
\text { comportamento } \\
\text { tático } \\
\text { de acordo com o } \\
\text { round, a luta e o } \\
\text { resultado do } \\
\text { combate. }\end{array}$ & $\begin{array}{c}\text { Vencedores realizaram } \\
\text { menor número de ataques } \\
\text { indiretos e executaram mais } \\
\text { contra-ataques, ataques } \\
\text { antecipatórios, simultâneos } \\
\text { e posteriores as ações dos } \\
\text { oponentes. Ataques diretos e } \\
\text { antecipatórios são os mais } \\
\text { frequentes no terceiro } \\
\text { round. }\end{array}$ \\
\hline $\begin{array}{l}\text { Menescardi } \\
\text { et al., } 2012\end{array}$ & $\begin{array}{l}30 \text { atletas do } \\
\text { sexo masculino } \\
\text { e } 30 \text { do sexo } \\
\text { feminino. }\end{array}$ & $\begin{array}{c}\text { Análise das lutas } \\
\text { finais e semifinais } \\
\text { da competição nos } \\
\text { critérios: } \\
\text { pontuação obtida, } \\
\text { ações totais, tipo } \\
\text { de ação tática, } \\
\text { zona de ataque, } \\
\text { tipo de técnica e } \\
\text { lateralidade. }\end{array}$ & $\begin{array}{c}\text { Avaliar o } \\
\text { comportamento } \\
\text { técnico-tático em } \\
\text { função do sexo e } \\
\text { da categoria de } \\
\text { peso. }\end{array}$ & 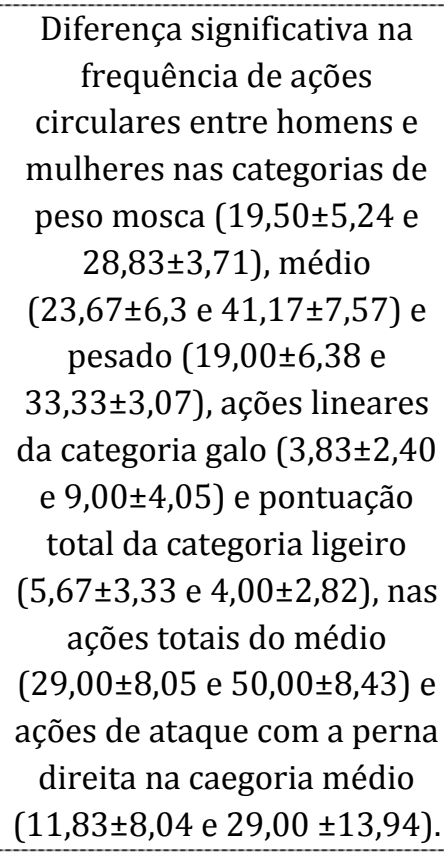 \\
\hline Pyciarz, 2011 & $\begin{array}{c}112 \text { atletas de } \\
\text { elite do sexo } \\
\text { masculino. }\end{array}$ & $\begin{array}{c}\text { Análise secundária } \\
\text { direta a partir de } \\
\text { ficha de } \\
\text { observação }\end{array}$ & $\begin{array}{l}\text { Analisar a } \\
\text { estrutura técnica e } \\
\text { possíveis } \\
\text { modificações após } \\
\text { a implementação }\end{array}$ & $\begin{array}{l}\text { O chute circular na altura do } \\
\text { tronco é a técnica mais } \\
\text { frequente em ambas as } \\
\text { competições, com leve } \\
\text { declínio em 2009. Chutes na }\end{array}$ \\
\hline
\end{tabular}




\begin{tabular}{|c|c|c|c|c|}
\hline & & & $\begin{array}{l}\text { do sistema } \\
\text { eletrônico de } \\
\text { pontuação. }\end{array}$ & $\begin{array}{c}\text { altura da cabeça } \\
\text { aumentaram de } 12 \% \text { em } \\
2008 \text { para } 43 \% \text { em } 2009 \\
\text { após a valorização da } \\
\text { pontuação nesta região. }\end{array}$ \\
\hline $\begin{array}{c}\text { Santos et al., } \\
2011\end{array}$ & $\begin{array}{l}48 \text { atletas do } \\
\text { sexo } \\
\text { masculino. }\end{array}$ & $\begin{array}{l}\text { Sistema de análise } \\
\text { tempo-movimento }\end{array}$ & $\begin{array}{l}\text { Determinar a } \\
\text { relação entre } \\
\text { tempo de ataque e } \\
\text { pausa em } \\
\text { campeonatos } \\
\text { internacionais de } \\
207 \text { e } 2008 .\end{array}$ & $\begin{array}{c}\text { A relação esforço:pausa } \\
\text { encontrada foi de } \\
\text { aproximadamente } 1: 7 .\end{array}$ \\
\hline $\begin{array}{l}\text { Tornello et } \\
\text { al., } 2014\end{array}$ & $\begin{array}{l}\text { Atletas jovens } \\
\text { de ambos os } \\
\text { sexos. }\end{array}$ & $\begin{array}{c}\text { Ação tática, } \\
\text { execução técnica, } \\
\text { lateralidade e } \\
\text { efetividade. }\end{array}$ & $\begin{array}{l}\text { Definir o perfil } \\
\text { técnico-tático de } \\
\text { competidores } \\
\text { juvenis a partir de } \\
\text { novas regras de } \\
\text { competição. }\end{array}$ & 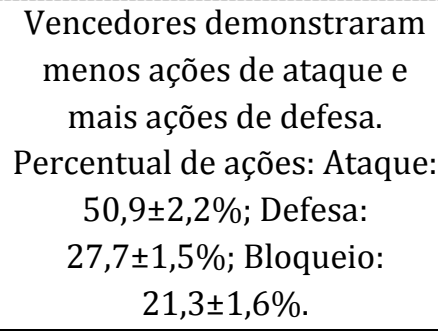 \\
\hline
\end{tabular}

A Tabela 2 mostra estudos com protocolos sofisticados que identificaram e caracterizam ações de combate complexos de serem desenvolvidos e replicados, pois dependem da precisão no relato dos critérios da observação técnico-tática (Menescardi, et al., 2012; Casolino, et al., 2012; Kazemi, et al., 2013). Merecem destaques quatro artigos selecionados com direcionamento específico para análise de time-motion ou/e técnica e tática em revistas internacionais com fator de impacto maior que 1.0 (Tornello, et al., 2013; Bridge, et al., 2011; Santos, et al., 2011; Tornello, et al., 2014). Essas investigações conduziram estudos com validade externa elevada e apresentaram maiores evidências de validade interna quanto aos procedimentos avaliados na escala de PEDro.

Recentemente, autores indicaram uma relação positiva entre análise de auto-eficácia percebida dos aspectos técnico-táticos (i.e., ataque direto, ataque indireto, contra-ataque por antecipação, contra-ataque simultâneo, contra-ataque posterior, chute linear, chute circular, chute com giro, chute no tronco e chute na cabeça) em função do êxito do combate e do gênero, sendo que não foram observadas diferenças entre homens e mulheres (Estevan, Álvarez, \& Castillo, 2016). Todavia, perdedores e ganhadores percebem diferente a eficácia do combate em função das ações desempenhadas durante o combate (Estevan, Álvarez \& Castillo, 2016).

Por exemplo, autores estabelecem que as ações de ataque observadas no TKD são provenientes da iniciativa do atleta ou em resposta para os ataques do adversário, que podem ser direto, indireto ou sequenciado e/ou aos contra-ataques que podem ser realizados antecipadamente, simultaneamente ou posteriormente à ação do oponente. Em contrapartida, movimentos defensivos são caracterizados pelos bloqueios e/ou esquivas aos gestos do adversário (González, et al., 2011). Poucas pesquisas revelaram adaptações na organização técnico-tática de lutadores elite em comparação com não-elite (i.e., Casolino, et al., 2012; Falcó, et al., 2012; Kazemi, et al., 2013; Menescardi, et al., 2012). Por exemplo, atletas de elite, em 2008, adotaram uma tática conservativa, utilizando mais ações de contra-ataque para pontuar (Kazemi, et al., 2010), diferente de dados com lutadores universitários, mostram que as ações de ataque são mais frequentes do que as ações de defesa em ambos os sexos, com predominância de chutes circulares e preferência para técnicas desferidas na altura do tronco (Falcó, et al., 2012).

As pesquisas da Tabela 1 mostram que no contexto variável e imprevisível da luta de TKD, os atletas necessitam de um exímio repertório motor para criação de estratégias que consideram o conhecimento espaço-temporal combinado com distância, posicionamento, postura e deslocamentos do adversário, assim como ações do próprio atleta (González, et al., 2011; GómezCastañeda, 2005) para aplicar golpes em diferentes orientações, com membros direito ou esquerdo, perna da frente ou de trás, em condição ofensiva ou defensiva e até mesmo para executar movimentos de esquiva ou bloqueio (Kim, et al., 2010; Gonzalez, 2011). Referências atuais da 
Tabela 2 apontam para o aumento da incidência de chutes na altura da cabeça desde 2012, contabilizando no total de todos os combates 51 ações efetivas, comparadas com 28, no ano de 2008, de acordo com análise realizada com 31\% dos combates que ocorreram no evento (Kruszewski, et al., 2014). Ainda, de acordo com os mesmos autores, apesar da modificação da regra de competição, que passou a valorizar com maior pontuação golpes aplicados na altura da cabeça, também foi crescente o número de golpes efetivos na altura do tronco quando comparadas à edição de 2012 com 137 golpes com a de 2008, esta com 123 (Kruszewski, et al., 2014).

Em análise longitudinal, os estudos sugerem fortes tendências de especialização competitiva sob influência das modificações nas regras e pela inclusão do colete, que modificaram em razão da necessidade em tornar a luta atrativa e, ao mesmo tempo, melhorar o sistema de pontuação, tornado-o menos subjetivo (Pieter, 1991; Pyciarz, 2011; Kruszewski, et al., 2014; Ouergui, et al., 2014). Especialmente, quando se comparam dados prévios e após a introdução do colete eletrônico na modalidade (Pyciarz, 2011; Kruszewski, et al., 2014). Por exemplo, comparações na quantidade total de ataques e defesas entre 2012 e 2008 mostram aumento de 64 para 86 chutes em situação de ataque e de 93 para 113 ações de defesa (Kruszewski, et al., 2014).

\subsection{Caracterização do combate de TKD}

Nesta seção serão apresentadas as características de uma luta de TKD, a partir de achados da literatura com atletas de nível nacional e internacional. Dentre os aspectos pesquisados estão a estrutura temporal durante o período de esforço e pausa, as técnicas mais utilizadas e as respostas fisiológicas ocorridas no decorrer de uma luta oficial ou em simulação.

Durante as competições, os atletas utilizam técnicas de ataque e de defesa para pontuação (Kazemi, et al., 2006, 2009, 2010), sendo que tais ações técnicas podem ser provenientes de socos e/ou chutes. No entanto, 98\% dos movimentos se originam das técnicas de chutes (Kazemi, et al., 2006), com aumento das técnicas realizadas na altura da cabeça após as modificações de regras e introdução do colete eletrônico (Kruszewski, et al., 2014). Entre 2000 e 2004, os atletas de ambos os sexos pontuaram mais utilizando técnicas de ataque de chute (Kazemi, et al., 2006, 2009), assim como observado com atletas juvenis (Casolino, et al., 2012). Porém, em 2008, os atletas pontuaram mais utilizando técnicas de defesa simples, apesar de valerem apenas um ponto (Kazemi, et al., 2010), o que parece persistir em estudos mais atuais (Tornello, et al., 2014; Falcó, et al., 2014; Kruszewski, et al., 2014; López-López, et al., 2015). Essa diferença, observada na Tabela 3, pode ser parcialmente explicada pelas mudanças das regras da modalidade durante o período entre as competições mencionadas, fato que modifica a estratégia utilizada na luta. Apesar da perda de peso e do estado nutricional serem assuntos polêmicos entre atletas do TKD em relação ao estado de saúde física, análises de performance durante o período do Ramadan (mês islâmico em que ocorre a prática de jejum) mostraram que o estado nutricional dos atletas não interferiu diretamente na frequência de ataques e na eficácia técnica em TKD de alto rendimento (Kordi, et al., 2011).

Muitas vezes, é dada grande atenção à quantidade de ações técnicas realizadas e não à sua eficiência. Porém, a quantidade de ataques não discriminou atletas medalhistas e não medalhistas, nem diferenciou atletas de elite (Santos, et al., 2011). Em contrapartida, a eficiência na aplicação da técnica pode diferenciar os atletas durante uma luta (Santos, et al., 2011). Em outro estudo sobre o volume de técnicas, houve diferença apenas quando consideradas as categorias de peso (Bridge, et al., 2011). Os atletas da categoria de peso $<68 \mathrm{~kg}$ atacaram menos do que os atletas da categoria $<58 \mathrm{~kg}$ durante os Jogos Olímpicos de Beijing (Bridge, et al., 2011). De acordo com Santos et al. (2011) o fato de atletas da categoria mais pesada atacarem menos e serem mais lentos durante o combate estaria relacionado ao fato de possuírem mais massa muscular em seus membros, gastando assim mais energia ao efetuarem chutes e socos. Em atletas de elite, não existe um acordo entre os estudos sobre o efeito da categoria de peso nas ações técnico-táticas (Bridge, et al., 2011). Portanto, essa variável merece atenção, especialmente, após a última modificação das regras (WTF, 2017).

O que se sabe é que houve um aumento no número de ataques nos últimos anos e que esse ataque se origina principalmente por parte do lutador que está em desvantagem no placar, por estar em situação de desvantagem ou por falta de uma estratégia de luta - quando em situação 
adversa - os lutadores atacam longo dos rounds de uma luta, os atletas aumentam o número de ataques (Santos, et al., 2011), com maior frequência (Matsushigue, et al., 2009), o que não indica eficiência.

Tabela 3. Técnicas apresentadas por atletas de taekwondode ambos os sexos nos Jogos Olímpicos de 2000, 2004 e 2008 (Kazemi et al., 2006, 2009, 2010).

\begin{tabular}{lcccccc}
\hline & \multicolumn{2}{c}{ Sydney $\mathbf{2 0 0 0}$} & \multicolumn{2}{c}{ Athenas 2004 } & \multicolumn{2}{c}{ Beijing 2008 } \\
& M (n=54) & $\mathbf{F ~ ( n = 4 8 ) ~}$ & $\mathbf{M}(\mathbf{n = 6 4 )}$ & $\mathbf{F}(\mathbf{n = 6 0 )}$ & $\mathbf{M}(\mathbf{n = 6 4 )}$ & $\mathbf{F}(\mathbf{n = 6 4 )}$ \\
\hline Total de chutes ofensivos & 275 & 273 & 667 & 416 & 179 & 146 \\
Total de chutes defensivos & 204 & 242 & 351 & 268 & 214 & 202 \\
Total de socos & 3 & 1 & 0 & 0 & 2 & 0 \\
Total & 482 & 516 & 1018 & 684 & 395 & 348 \\
\hline M = Masculino; F = Feminino & & & & & &
\end{tabular}

Outro aspecto pode diferenciar os atletas que venceram as lutas dos demais. 0 atleta vitorioso apresenta perfil motor diferenciado e consegue ter maior eficiência de ataque e ainda manter ou reduzir pouco a quantidade desses ataques ao longo da luta (Kazemi, et al., 2006). Dentre os lutadores que não conseguiram êxito no combate, a maior concentração de pontos aconteceu no primeiro e segundo rounds com grande redução percentual durante o terceiro round (Kazemi, et al., 2006). Entre atletas do sexo feminino durante os Jogos Pan-americanos 2007 não houve associações entre o tipo e a frequência de técnicas utilizadas e o sucesso competitivo (Santos, et al., 2011). Também não houve diferença no número de ataques ao longo da luta (Markovic, et al., 2008). Para todos os casos, parece ser importante um planejamento estratégico de luta para diferentes situações, esteja o atleta em vantagem ou em desvantagem no placar para que possa sair com a vitória. Descrever a quantidade de ataques e diferentes comparações entre os mesmos se torna necessário para compreender a temporalidade e cadência características da modalidade (Campos, et al., 2012; Santos, et al., 2011).

O TKD é um esporte dinâmico, com característica intermitente (Campos, et al., 2012), pois é executado com ações em diferentes intensidades e durações, aqui classificadas genericamente em três categorias: ações de ataque (golpes), step e pausa. Durante campeonatos internacionais, as ações de ataque, step e pausa duraram em média $1,3 \mathrm{~s} \pm 0,4 \mathrm{~s} ; 9,2 \mathrm{~s} \pm 3,9 \mathrm{~s}$ e $6,0 \mathrm{~s} \pm 3,9 \mathrm{~s}$, respectivamente (Santos, et al., 2011). Entre as diferentes categorias de peso, os atletas de categorias mais leves aplicaram ações de ataque mais frequentemente do que os atletas de categorias mais pesadas (Santos, et al., 2011).

0 tempo empregado em cada atividade durante um round da luta de TKD, foi apresentado em estudo prévio, sendo $12 \pm 3 \%$ em movimentos de luta, $49 \pm 5 \%$ em ações preparatórias, $13 \pm 8 \%$ em ações não preparatórias e $26 \pm 14 \%$ em ações de interrupção (Bridge, et al., 2011). Assim, entendemos que a especificidade da preparação do atleta possa acontecer seguindo esses referenciais, pois entre os atletas de nível internacional foram observadas variações entre as competições. Essas mesmas variações podem acontecer em competições nacionais, estaduais e regionais.

Após a descrição da distribuição temporal, foi possível verificar a relação entre as ações, momentos de luta (alta intensidade) e sem luta (ações de baixa intensidade - step e pausa). Essas relações são apresentadas na Tabela 4.

A relação entre momentos de luta e sem luta traz implicações fisiológicas importantes, dado que uma ação de curta duração (como é o caso das ações de ataque, com alta intensidade), podem ser intercaladas por até sete vezes em um mesmo período com atividade de baixa intensidade (Campos, et al., 2012; Butios \& Tasika, 2007). Isso tem se mostrado suficiente para a ressíntese de creatina fosfato (CP), o que indica a ativação do metabolismo anaeróbio alático durante as ações de alta intensidade (Campos, et al., 2012; Butios \& Tasika, 2007). Adicionalmente, a temporalidade da luta é influenciada pelo estilo, peso, gênero, nível dos atletas, round da luta e fase da competição (Bridge, et al., 2011).

Primordialmente, estudos com observações de tempo-movimento não verificaram diferenças entre categorias de peso para tempo de esforço e pausa, embora tenha ocorrido 
diferença entre os rounds (Bridge, et al., 2011). A relação entre os momentos de luta (no qual ocorre contato entre os lutadores), sem luta (sem contato entre os lutadores) e pausa foram de 1 para $7,8 \mathrm{~s}$ $\pm 4,2 \mathrm{~s} ; 5,5 \mathrm{~s} \pm 1,2 \mathrm{~s}$ e $4,9 \mathrm{~s} \pm 2$,1s no primeiro, segundo e terceiro round, respectivamente (Bridge, et al., 2011). Conhecer a dinâmica das lutas se torna necessário para que se possa compreender as respostas fisiológicas e também para elaboração do processo de preparação física específica dos atletas de TKD. Após observarmos a temporalidade da luta, temos condições de entender melhor as repostas fisiológicas que ocorre em uma competição oficial.

Tabela 4. Movimentos de alta intensidade e baixa intensidade no taekwondo.

\begin{tabular}{lcccc}
\hline Referência & Estilo & Situação de análise & População & $\begin{array}{c}\text { Relação } \\
\text { esforço:pausa }\end{array}$ \\
\hline $\begin{array}{l}\text { Bridge et al. } \\
\text { (2011) }\end{array}$ & WTF & $\begin{array}{c}\text { Campeonato } \\
\text { Mundial }\end{array}$ & $\begin{array}{c}\text { Adulto masculino faixa preta - } \\
\text { Internacional }\end{array}$ & $1: 6$ \\
\hline $\begin{array}{l}\text { Campos et } \\
\text { al. (2012) }\end{array}$ & WTF & Simulação de Luta & $\begin{array}{c}\text { Adulto masculino faixa preta - Nacional / } \\
\text { Internacional }\end{array}$ & $1: 7$ \\
\hline $\begin{array}{l}\text { Heller et al. } \\
(1998)\end{array}$ & ITF & Simulação de luta & $\begin{array}{c}\text { Adulto e juvenil masculino e feminino } \\
\text { faixa preta - Nacional }\end{array}$ & $1: 3-1: 4$ \\
\hline $\begin{array}{l}\text { Matsushigue } \\
\text { et al.(2009) }\end{array}$ & STF & $\begin{array}{c}\text { Campeonato } \\
\text { Nacional }\end{array}$ & Adulto masculino faixa preta - Nacional & $1: 6$ \\
\hline $\begin{array}{l}\text { Santos et al. } \\
(2011)\end{array}$ & WTF & $\begin{array}{c}\text { Campeonato } \\
\text { Mundial } \\
\text { Jogos Olímpicos }\end{array}$ & Adulto faixa preta Internacional & $1: 7$ \\
\hline $\begin{array}{l}\text { Tornello et } \\
\text { al. (2013) }\end{array}$ & WTF & $\begin{array}{c}\text { Campeonato } \\
\text { Italiano Cadete }\end{array}$ & Cadete masculino faixa preta - Nacional & $1: 2-1: 3$ \\
\hline
\end{tabular}

Para atletas jovens, a estrutura temporal é similar, independentemente do sexo, divisão de peso e fase da competição. As diferenças emergem na frequência de ocorrência de fases de combate ao longo dos rounds (luta: $42,4 \pm 0,5 \%$; sem luta: $44,5 \pm 0,7 \%$; pausa: $13,1 \pm 0,9 \%$ ) e em sua duração média (luta: 2,8 $\pm 1,0$ s; sem luta: 6,5 $\pm 1,8 \mathrm{~s}$; pausa: 13,7 $\pm 5,0 \mathrm{~s}$ ) (Tornello, et al., 2013). Como mostra a Tabela 2, foi encontrada uma relação de 1:2 para tempo de contato e sem contato, ao passo que uma proporção de 1:3 surgiu quando considerado tempo de luta em relação à soma dos momentos sem luta e pausa. Durante a fase de luta, $5 \pm 1$ movimentos táticos e $4 \pm 1$ ações técnicas eram realizadas, com duração de 0,6 $\pm 0,1$ s e $0,7 \pm 0,1$ s, respectivamente (Tornello, et al., 2013).

Em relação ao perfil técnico-tático, foi analisado o perfil de 50 atletas jovens em competições oficiais de TKD, utilizando um protocolo que avaliava ações táticas (ataque, defesa e blocos de movimentos), execuções técnicas (de 1 a 4 pontos), pernas chutando (dianteira/traseira combinada com o lado direito/esquerdo) eficácia técnica (Tornello, et al., 2014). Diferenças foram encontradas entre todas as tipologias de ação durante o combate (Ataque: 50,9 $\pm 2,2 \%$; Defesa: 27,7 $\pm 1,5 \%$; Blocos: $21,3 \pm 1,6 \%$ ), nas quais os vencedores mostram menor número de ações de ataque e muito mais ações de defesa em relação aos perdedores. Vencedores mostraram ser mais eficientes para variáveis técnicas e táticas (Tornello, et al., 2014). Ao considerar que a adoção do novo sistema eletrônico requer atletas para executar ações técnicas corretas para ter uma pontuação atribuída, os técnicos devem enfatizar a eficácia das técnicas de pontuação e ajudar os atletas a melhorar eficazmente as suas capacidades de defesa e de resposta rápida (Tornello, et al., 2014).

A Tabela 5 ilustra os parâmetros técnico-táticos analisados nos principais estudos selecionados. As recentes mudanças nos regulamentos feitas pela WTF (WTF, 2017), visando aumentar a atratividade desse esporte de combate e simplificar as regras, a fim de serem compreendidas por um "telespectador médio", refletiu em modificações nos combates de TKD (Kruszewski, et al., 2014). Durante as lutas em torneios olímpicos, atletas do sexo feminino de Londres realizaram mais ataques, marcando mais pontos, quando comparados os Jogos Olímpicos Beijing (Kruszewski, et al., 2014). 0 maior efeito sobre a estrutura da luta foi a introdução de 3 pontos para chute na cabeça de um adversário, o que provocou diferenças entre lutadoras, de até 4 pontos, usando apenas uma técnica de chute com rotação, utilizadas com muito mais frequência, atualmente, com orientação para cabeça (Kruszewski, et al., 2014). Analisando as ações técnicas usadas por atletas de TKD durante o torneio olímpico em Sydney 2000 e Atenas 2004, os estudos 
encontraram aumento estatisticamente significativo em ataques em direção à cabeça do adversário (Kruszewski, et al., 2009). As técnicas de chutes descendentes (neryo chagi) e chutes giratórios na altura da cabeça (dwi dollyo chagi) foram mais frequentemente realizadas no torneio em Atenas (Pyciarz, 2011). As novas regras também apresentam indicativos de aumento de ações de defesa, quando comparadas quantidades de ações de ataque e de defesa (Kruszewski, et al., 2014).

Tabela 5. Parâmetros técnico-táticos em atletas de taekwondo.

\begin{tabular}{|c|c|c|c|c|}
\hline Referência & $\begin{array}{l}\text { Situação de } \\
\text { análise }\end{array}$ & População & Tipo de ação & Lateralidade \\
\hline $\begin{array}{l}\text { Casolino et } \\
\text { al., } 2012\end{array}$ & $\begin{array}{l}\text { Campeonato } \\
\text { Nacional }\end{array}$ & $\begin{array}{l}\text { Cadete } \\
\text { masculino } \\
\text { faixa preta }\end{array}$ & $\begin{array}{c}\text { Ofensiva }(91,6 \pm 12 \%) \text { e defensiva } \\
(8,4 \pm 12 \%)\end{array}$ & $\begin{array}{c}\text { Perna de trás } \\
(94,4 \pm 7,8 \%) \text { e } \\
\text { perna da frente } \\
(5,8 \pm 7,8 \%)\end{array}$ \\
\hline $\begin{array}{l}\text { Cular et al., } \\
2011\end{array}$ & $\begin{array}{l}\text { Jogos Olímpicos } \\
\text { de } 2008\end{array}$ & $\begin{array}{l}\text { Adulto } \\
\text { masculino e } \\
\text { feminino faixa } \\
\text { preta elite }\end{array}$ & $\begin{array}{l}\text { Maior pontuação pra chutes } \\
\text { defensivos na altura do tronco }\end{array}$ & --- \\
\hline $\begin{array}{l}\text { Falcó et al., } \\
2012\end{array}$ & $\begin{array}{l}\text { Campeonato } \\
\text { Espanhol } \\
\text { Universitário de } \\
2011\end{array}$ & $\begin{array}{l}\text { Adulto } \\
\text { masculino e } \\
\text { feminino }\end{array}$ & $\begin{array}{l}\text { Média de } 30 \text { ações e } 4 \text { pontos por } \\
\text { luta masc.; Atletas masc. utilizam } \\
\text { mais ataque do que contra-ataque; } \\
\text { Prioridade para chutes no tronco }\end{array}$ & -- \\
\hline $\begin{array}{l}\text { Falcó et al., } \\
2014\end{array}$ & $\begin{array}{l}\text { Campeonato } \\
\text { Espanhol } \\
\text { Universitário de } \\
2011\end{array}$ & $\begin{array}{l}\text { Adulto } \\
\text { masculino e } \\
\text { feminino }\end{array}$ & $\begin{array}{l}\text { Mais ataques do que contra- } \\
\text { ataques; vencedores contra- } \\
\text { atacaram mais e realizam menos } \\
\text { ataque indireto que perdedores }\end{array}$ & -- \\
\hline $\begin{array}{l}\text { Iglesias et al., } \\
2010\end{array}$ & $\begin{array}{l}\text { Campeonato } \\
\text { Mundial }\end{array}$ & Adulto elite & $\begin{array}{c}\text { Ações por round: } 1 \text { - R }(31 \%), 2^{\circ} \mathrm{R} \\
(30,3 \%), 3^{\circ} \mathrm{R}(38,4 \%) \text { e } 4 \% \mathrm{R} \\
(0,4 \%) \\
\text { Efetividade: } 1 \% \mathrm{O}(7,5 \%), 2^{\circ} \mathrm{R} \\
(8,5 \%), 3^{\circ} \mathrm{R}(8,3 \%) .\end{array}$ & -- \\
\hline $\begin{array}{l}\text { López-López } \\
\text { et al, } 2015\end{array}$ & $\begin{array}{l}\text { Jogos Olímpicos } \\
\text { de } 2012\end{array}$ & $\begin{array}{l}\text { Adulto faixa } \\
\text { preta elite }\end{array}$ & $\begin{array}{l}\text { Ações circulares são mais } \\
\text { utilizadas. Há mais ações de giro } \\
\text { com a guarda aberta. }\end{array}$ & $\begin{array}{l}\text { Em distância curta } \\
\text { há maior execução } \\
\text { de chutes com a } \\
\text { perna de trás. }\end{array}$ \\
\hline $\begin{array}{l}\text { Matsushigue } \\
\text { et al., } 2009\end{array}$ & $\begin{array}{l}\text { Campeonato } \\
\text { Nacional } \\
\text { Brasileiro de } \\
\text { TKD STF }\end{array}$ & $\begin{array}{l}\text { Adulto } \\
\text { masculino } \\
\text { faixa preta }\end{array}$ & $\begin{array}{l}\text { Chutes por atleta e por luta: } \\
27 \pm 13 \text {. O chute lateral foi o mais } \\
\text { aplicado nos combates. }\end{array}$ & 50 \\
\hline $\begin{array}{l}\text { Santos et al., } \\
2011\end{array}$ & $\begin{array}{l}\text { Campeonato } \\
\text { Mundial (2007) } \\
\text { e Jogos } \\
\text { Olímpicos } \\
\text { (2008) }\end{array}$ & $\begin{array}{l}\text { Adulto } \\
\text { masculino } \\
\text { faixa preta } \\
\text { elite }\end{array}$ & Golpes por round: 15 a 20 & -- \\
\hline $\begin{array}{l}\text { Tornello et } \\
\text { al., } 2014\end{array}$ & $\begin{array}{l}\text { Campeonato } \\
\text { italiano cadete } \\
\text { de } 2010\end{array}$ & $\begin{array}{c}\text { Cadete } \\
\text { masculino e } \\
\text { feminino faixa } \\
\text { preta }\end{array}$ & $\begin{array}{c}\text { Vencedores realizaram mais ações } \\
\text { de defesa }(21,7 \pm 16,3 \%) \text { do que de } \\
\text { ataque }(18,4 \pm 12,3 \%) \text {; Mais } \\
\text { técnicas de } 1 \text { ponto }(68,5 \pm 1,7 \%) \text { e } \\
\text { de } 3 \text { pontos }(16,2 \pm 1,6 \%) \text {. } \\
\text { Maior frequência de ataques } \\
(50,9 \pm 2,2 \%) \text { comparada com } \\
\text { defesas }(27,7 \pm 1,5 \%) \text { e bloqueios } \\
(21,3 \pm 1,6 \%) \text {. }\end{array}$ & 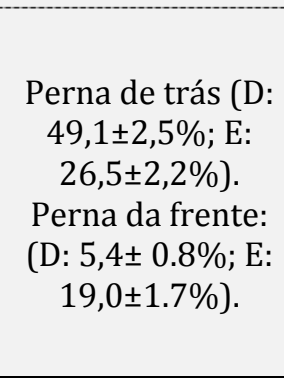 \\
\hline
\end{tabular}

\section{Conclusão}

É possível observar a partir dos estudos descritos que um combate de TKD é caracterizado por ações de alta intensidade intervaladas com ações de baixa intensidade, ou até mesmo de inatividade. Tal parâmetro é relevante para o treinamento e preparação física dos atletas da modalidade, de modo que a temporalidade da luta seja evidente também durante as sessões de 
treino a fim de prepará-los para a demanda metabólica e fisiológica encontrada na competição de acordo com as categorias de peso, sexo dos competidores e nível do torneio.

Este estudo revela fatores determinantes para aplicação prática dos resultados encontrados. Primeiro, os referenciais obtidos em competições de alto rendimento necessitam ser inseridos em práticas contextualizadas no treino. Percentuais relativos ao total de golpes por competição da quantidade de socos e chutes ofensivos reduziram em cerca de $40 \%$ ao longo dos anos. Em contrapartida, os contra-ataques mantém os percentuais relativos ao total de golpes na competição, isso sugere que treinar ações competitivas defensivas, como contra-ataque, pode gerar maior probabilidade de sucesso, pois essas ações estão associadas com melhores resultados competitivos. Em segundo lugar, a relação entre movimentos de alta intensidade e baixa intensidade está conectada com a classe de idade, atletas juvenis apresentam relação entre 1:2 e 1:4, enquanto atletas adultos apresentam entre 1:6 e 1:7, isso, particularidade, sugere uma divisão da faixa etária para treinamentos específicos, de acordo com a demanda de intensidade que concerne cada idade. Terceiro, as ações em competições de alto rendimento modificaram ao longo dos anos, o chute lateral era o mais aplicado, entretanto, as últimas análises indicam as ações circulares como as mais utilizadas, especialmente, em distâncias curtas, há maior execução de chutes com a perna de trás, o que mostra a importância em combinar distância com tipo de ataque. Atletas de TKD de sucesso parecem utilizar chutes altos como melhor estratégia para vencer um combate, de acordo com as regras atuais que valorizam a pontuação para chutes na cabeça e que são subordinadas ao uso do colete eletrônico, que modificou a lógica do combate e que necessariamente, precisa ser utilizado em treinamentos. Essas informações também podem ser utilizadas como suporte para preparação física ligada à cada ação específica do combate.

As implicações teóricas desse trabalho mostram ações determinantes e efetivas no combate, isso pode ser utilizado para a criação de modelos técnico-táticos e fisiológicos por estudiosos, técnicos e treinadores para serem aplicados em competições e treinamentos ou avaliações físicas, análogos aos dados encontrados.

\section{Referências}

Bridge, C., Jones, M.A., \& Drust, B. (2011). The activity profile in international Taekwondo competition is modulated by weight category. International Journal of Sports Physiology and Performance, 6(3), 344-357.

Butios, S., \& Tasika, N. (2007). Changes in heart rate and blood lactate concentration as intensity parameters during simulated Taekwondo competition. The Journalof Sports Medicine and Physical Fitness, 47(2), 179-185.

Campos, F.A., Bertuzzi, R., Dourado, A.C., Santos, V.G., \& Franchini, E. (2012). Energy demands in Taekwondo athletes during combat simulation. European Journal of Applied Physiology, 112(4), 1221-1228.

Casolino, E., Lupo, C., Cortis, C., Chiodo, S., Minganti, C., \& Capranica, L. (2012). Technical and Tactical Analysis of Youth Taekwondo Performance. Journal of Strength and Conditioning Research, 26(6), 1489-1495.

Chaabène, H., Franchini, E., Miarka, B., Selmi, M.A., Mkaouer, B., \& Chamari, K. (2014). Time-Motion Analysis and Physiological Responses to Karate Official Combat Sessions: Is There a Difference Between Winners and Defeated Karatekas?. International Journal of Sports Physiology and Performance, 9(2), 302-308.

Cular, D., Krstolovic, S., \& Tomljanovoc, M. (2011). The differences between medalists and nonmedalists at the 2008 Olympic Games Taekwondo Tournament. Human Movement, 12(12), 165-170.

De Morton, N. (2009). The PEDro scale is a valid measure of the methodological quality of clinical trials: a demographic study. The Australian Journal of Physiotherapy, 55(2), 129-133.

Del Vecchio, F.B., Silva, J.J.R., \& Farias, C.B. (2015). Análise temporal de combates de Muay Thai de nível nacional: Efeitos da fase competitiva. Revista de Artes Marciales Asiáticas, 10(1), 34-41.

Estevan, I., Álvarez, O., \& Castillo, I. (2016). Autoeficacia percibida y rendimiento técnico-táctico en taekwondistas universitarios. Cuadernos de Psicología del Deporte, 16(2), 51-64. 
Falcó, C., Estevan, I., Alvarez, O., Morales-Sánchez, V., \& Hernández-Mendo, A. (2014). Tactical Analysis of the Winners' and Non-Winners' Performances in a Taekwondo University Championship. International Journal of Sports Science \& Coaching, 9(6), 1407-1416.

Falcó, C., Landeo, R., Menescardi, C., Bermejo, J.L., \& Estevan, I. (2012). Match Analysis in a University Taekwondo Championship. Advances in Physical Education, 2(1), 28-31.

Fargas, I. (1990). Taekwondo - Alta competición. Barcelona: Total Press.

Gómez-Castañeda, P. E. (2005). Dirección y control del proceso de entrenamiento en el Taekwondo. Ciencia Deporte y Cultura Física, 1(1), 58-68.

González, C. (2011). Caracterización Técnico-Táctica de la competición de combate de alto nivel de Taekwondo. Efectividad de las acciones tácticas (tese de doutoramento). Universitat de Barcelona, Barcelona.

González, C., Iglesias, X., Mirallas, J., \& Esparza, G. (2011). Sistematización de la acción táctica en el Taekwondo de alta competición. Apunts Educación Física y Deportes, 103, 56-67.

Heller, J., Peric, T., Dlouhá, R., Kohlíková, E., Melichna, J., \& Novákivá, H. (1998). Physiological profiles of male and female Taekwondo (ITF) black belts. Journal of Sports Sciences, 16(3), 243-249.

Iglesias, X., Gasset, A., González, C., \& Anguera, M.T. (2010). Interacción competitiva y presión ambiental en deportes de combate: aplicación de la metodología observacional. Revista Iberoamericana de Psicología del Ejercicio y el deporte, 5(22), 267-282.

Kazemi, M., Casella C, \& Perri, G. (2009). 2004 Olympic Taekwondo Athletes profile. The Journal of Canadian Chiropractic Association, 53(2), 144-152.

Kazemi, M., De Ciantis, M.G., \& Rahman, A. (2013). A profile of the Youth Olympic Taekwondo Athlete. The Journal of Canadian Chiropractic Association, 57(4), 293-300.

Kazemi, M., Perri, G., \& Soave, D. (2010). A profile of 2008 Olympic Taekwondo Competitors. The Journal of Canadian Chiropractic Association, 54(4), 243-249.

Kazemi, M., Waalen, J., Morgan, C., \& White, A. (2006). A profile of Olympic Taekwondo competitors. Journal of Sports Science and Medicine, 5(CSSI), 114-121.

Kim, J.W., Kwon, M.S., Yenuga, S.S., \& Kwon, Y.H. (2010). The effects of target distance on pivot hip, trunk, pelvis, and kicking leg kinematics in Taekwondo roundhouse kicks. Sports Biomechanics, 9(2), 98-114.

Kim, Y. J. (2006). Taekwondo competição - O manual dos campeões. São Paulo: Editora do Brasil.

Kordi, R., Abdollahi, M., Memari, A.H., \& Najafabadi, M.G. (2011). Investigating two different training time frames during ramadan fasting. Asian Journal of Sports Medicine, 2(3), 205-210.

Kruszewski, A., Jagiełło, W., \& Pyzel, W. (2009). The effectiveness of used techniques in a Taekwondo fight in the Olympic Tournament in Sydney 2000 and Athens 2004. In G. Olchowik (Ed.), Wellness and prosperity in different phases of life (pp. 197-211). Lublin: Wydaw. NeuroCentrum.

Kruszewski, A., Kúzmicki, S., Podchul, A., \& Kruszewski, M. (2014). Effect of changes in the sports regulations on the fight of Taekwondo female players on the example of Beijing Olympic Tournaments 2008 and London 2012. Journal of Combat Sports and Martial Arts, 2(5), 97-100.

López-López, J.A., Menescardi, C., Estevan, I., Falcó, C., \& Hernández-Mendo. (2015). Análisis técnico-táctico en Taekwondo con coordenadas polares a través del software Hoisan. Cuadernos de Psicología del Deporte, 15(1), 131-142.

Lystad, R.P., Swain, M.S., \& Graham P.L. (2013). Risk factors for injury in Olympic-style competition Taekwondo: a systematic review. The Journal of Sports Medicine and Physical Fitness, 53(6), 655-664.

Marcovic, G., Vucetic, V., \& Cardinale, M. (2008). Heart Rate and lactate responses to Taekwondo fight in elite women performers. Biology of Sport, 25(2), 93-99.

Matsushigue, K.A., Hartmann, K., \& Franchini, E. (2009). Taekwondo: Physiological responses and match analysis. Journal of Strength and Conditioning Research, 23(4), 1112-1117.

Menescardi, C., Bermejo, J.L., Herrero, C., Estevan, I., Landeo, R., \& Falcó, C. (2012). Diferencias técnico tácticas en taekwondistas universitarios según sexo y categoría de competición. Revista de Artes Marciales Asiáticas, 7(2), 1-11.

Menescardi, C., Lopez-Lopez, J.A., Falcó, C., Hernandez-Mendo, A., \& Estevan, I. (2015). Tactical aspects of a National University Taekwondo Championship in relation to round and match outcome. Journal of Strength and Conditioning Research, 29(2), 466-471. 
Ouergui, I., Haddad, M., Hammami, N., \& Chamari, K. (2014). Time-Motion and Technical and Tactical Analysis of Taekwondo Competition. In M. Haddad (ed.), Performance Optimization in Taekwondo: From Laboratory to Field. Nevada: OMICS Group Incorporation. Disponível em https://www.esciencecentral.org/ebooks/taekwondo/pdf/time-motion-and-technical-andtactical-analysis-of-taekwondo-competition.pdf

Pieter, W. (1991). Performance characteristics of elite Taekwondo athletes. Korean Journal of Sport Science, 3, 94-117, 1991.

Pyciarz, T. (2011). Analysis of sport fight structure in Taekwondo during the Olympics in Beijing in 2008 and Senior World Championships in 2009 in terms of technical skills after regulation and implementation of the electronic system of score recording. Journal of Combat Sports and Martial Arts, 2(2), 109-115.

Santos, V.G.F., Franchini, E., \& Lima-Silva, A.E. (2011). Relationship between attack and skipping in Taekwondo contests. Journal of Strength and Conditioning Research, 25(6), 1743-1751.

Slimani, M., Chaabène, H., Miarka, B., \& Chamari, K. (2016). The Activity Profile of Elite Low-Kick Kickboxing Competition. International Journal of Sports Physiology and Performance, Epub ahead of print.

Tornello, F., Capranica, L., Chiodo S, Minganti, C., \& Tessitore, A. (2013). Time-motion analysis of youth Olympic Taekwondo combats. Journal of Strength and Conditioning Research, 27(1), 223-228.

Tornello, F., Capranica, L., Minganti, C., Chiodo, S., Condello, G., \& Tessitore, A. (2014). TechnicalTactical Analysis of Youth Olympic Taekwondo Combat. Journal of Strength and Conditioning Research, 28(4), 1151-1157.

World Taekwondo Federation - WTF. (2016).Taekwondo Competition Rules Altered to Make Sport 'Dazzle and Excite' Changes Adopted at WTF General Assembly in Canada. Disponível em http://www.worldtaekwondofederation.net/taekwondo-competition-rules-altered-to-makesport-dazzle-and-excite-changes-adopted-at-wtf-general-assembly-in-canada

World Taekwondo Federation - WTF. (2017). Rules and documents. Disponível em http://www.worldTaekwondofederation.net/rules-and-documents

\section{Author's biographical data}

Paula Avakian (Brasil), É formada pela Academia Brasileira de Treinadores do Comitê Olímpico do Brasil na modalidade Taekwondo. É graduada em Educação Física pela Escola de Educação Física e Esporte da USP e é sócia da Empresa Brasil Lutas, que presta assessoria para atletas. As áreas de interesse são, especialmente, lutas e modalidades de combate e treinamento esportivo. E-mail: paulaavakian@hotmail.com

Bianca Miarka (Brasil), É pós-doutoranda na Universidade Federal de Pelotas e bolsista CAPES PNPD, doutora em Biodinâmica pela Escola de Educação Física e Esporte da Universidade de São Paulo (2014). Possui graduação em Ciência do Esporte (2005) e especialização em Treinamento Esportivo (2007) pela Universidade Estadual de Londrina e mestrado em Educação Física pela Escola de Educação Física e Esporte da Universidade de São Paulo (2010). Possui como foco de pesquisa trabalhos em psicologia do esporte, análise técnico-tática e de tempo-movimento em esportes de combate. E-mail: miarkasport@hotmail.com

Abdallah Achour (Brasil), Possui graduação em Educação Física pela Universidade Estadual de Londrina (1986), mestrado em Educação Física, Atividade Física e Saúde pela Universidade Federal de Santa Catarina (1999) e doutorado em Biodinâmica do Movimento Humano pela Universidade de São Paulo (2006). Atualmente é professor titular da Universidade Estadual de Londrina. Tem experiência na área de Educação Física e Esporte, atuando principalmente nos seguintes temas: flexibilidade, alongamento, atividade física e pedagogia do esporte. E-mail: achour-junior@hotmail.com 